Tropical Journal of Pharmaceutical Research November 2017; 16 (11): 2637-2644

ISSN: $1596-5996$ (print); 1596-9827 (electronic)

(C) Pharmacotherapy Group, Faculty of Pharmacy, University of Benin, Benin City, 300001 Nigeria.

All rights reserved.

Available online at http://www.tjpr.org

Original Research Article

http://dx.doi.org/10.4314/tjpr.v16i11.10

\title{
Therapeutic effects of co-inhaled roflumilast or formoterol and fluticasone on asthma-induced ultrastructural changes in murine airways
}

\author{
Hussam AS Murad ${ }^{1,2 \star}$, Hamed S Habib ${ }^{3}$, Misbahuddin M Rafeeq ${ }^{1}$, Mansour I \\ Sulaiman $^{4}$, Amer S Abdulrahman ${ }^{5}$ and Mohamad-Nidal A Khabaz \\ ${ }^{1}$ Department of Pharmacology, Faculty of Medicine, Rabigh, King Abdulaziz University, Jeddah, Saudi Arabia, ${ }^{2}$ Department of \\ Pharmacology, Faculty of Medicine, Ain Shams University, Cairo, Egypt, ${ }^{3}$ Department of Pediatrics, ${ }^{4}$ Department of \\ Pharmacology, ${ }^{5}$ Department of Pathology, Faculty of Medicine, Rabigh, King Abdulaziz University, Jeddah, Saudi Arabia
}

*For correspondence: Email: hamurad@kau.edu.sa, HussamMurad@med.asu.edu.eg, muradha2000@yahoo.com; Tel: +966541541341

Sent for review: 18 August 2017

Revised accepted: 26 October 2017

\begin{abstract}
Purpose: To investigate the therapeutic effects of "inhaled" roflumilast and formoterol separately or combined with fluticasone on the ultrastructural airway changes in ovalbumin-induced asthmatic mice. Methods: The asthmatic mice were divided randomly into seven groups $(n=8)$ : positive control, vehicle, and five treated groups. The following treatments were given by inhalation (15 min once/day) for seven days: roflumilast $(500 \mu \mathrm{g} / \mathrm{kg})$, formoterol $(50 \mu \mathrm{g} / \mathrm{kg})$, fluticasone $(1000 \mu \mathrm{g} / \mathrm{kg})$, roflumilast + fluticasone $(500+1000 \mu \mathrm{g} / \mathrm{kg})$, and formoterol + fluticasone $(50+1000 \mu \mathrm{g} / \mathrm{kg})$. Ultrathin lung sections (50 - $70 \mathrm{~nm}$ thick) were examined by transmission electron microscopy.

Results: The asthmatic mice showed marked degenerative changes in bronchiolar epithelial cells. The alveolar septal walls were thickened with cellular changes and capillary congestion. The basement membranes showed marked thickening and the airway lumens contained abundant mucinous secretions. These ovalbumin-induced ultrastructural airway changes were markedly-reversed in the roflumilast + fluticasone group, moderately-reversed in the roflumilast, fluticasone, and formoterol + fluticasone groups, but were not affected in the formoterol group.

Conclusion: Co-inhalation of roflumilast + fluticasone significantly improved the ultrastructural airway changes than co-inhalation of formoterol + fluticasone in ovalbumin-asthmatic mice due to its antiinflammatory and antifibrotic effects.
\end{abstract}

Keywords: Asthma, Fluticasone Propionate, Formoterol, Roflumilast, Ovalbumin, Remodeling, Bronchiolar epithelium

Tropical Journal of Pharmaceutical Research is indexed by Science Citation Index (SciSearch), Scopus, International Pharmaceutical Abstract, Chemical Abstracts, Embase, Index Copernicus, EBSCO, African Index Medicus, JournalSeek, Journal Citation Reports/Science Edition, Directory of Open Access Journals (DOAJ), African Journal Online, Bioline International, Open-J-Gate and Pharmacy Abstracts

\section{INTRODUCTION}

In bronchial asthma the injured airway epithelium enhances airway inflammation and remodeling through secretion of proinflammatory mediators [1]. Airway remodeling occurs partly as a result of chronic inflammation. It is manifested by epithelial changes, goblet cell hyperplasia, sub- epithelial fibrosis, thickened smooth muscle layer, and increased vascularity. It leads to airway narrowing, hyperresponsiveness, edema, progressive declining of lung functions, and more need for medications [2]. The airway smooth muscle also secretes inflammatory mediators and its mass increases due to hypertrophy, hyperplasia, and deposition of extracellular 
matrix proteins [3]. In asthma, airway inflammation generally responds to treatments but unfortunately airway remodeling is resistant [4]. Inhaled corticosteroids (ICS) are the mainstay in asthma therapy; however, systemic side effects may occur at high doses [5].

Formoterol is a long-acting $\beta_{2}$ agonist (LABA) with rapid onset of bronchodilation. LABAs do not have clinically important anti-inflammatory effects, thus in treatment of asthma they are always combined with ICS [6]. Roflumilast is a selective phosphodiesterase (PDE) inhibitor which is approved as an add-on treatment for chronic obstructive pulmonary disease (COPD). PDE-4 inhibitors are ineffective bronchodilators but they are powerful anti-inflammatory agents [7]. In a recently-published work [8], it was concluded that co-inhalation of roflumilast and fluticasone significantly improved the inflammatory and histopathological changes than that of formoterol plus fluticasone in ovalbumin-asthmatic mice.

Studying the ultrastructural changes at cellular and subcellular levels using transmission electron microscopy (TEM) reveals more details and hence helps more understanding of the effects of the different treatments especially the anti-remodeling effect. Consequently, the current study was designed in OVA-sensitized and challenged mice to investigate the therapeutic effects of inhaled roflumilast and formoterol separately or combined with fluticasone on the ultrastructural airway changes.

\section{EXPERIMENTAL}

\section{Animals}

The study was carried out according to the International Guidelines for the Care and Use of Laboratory Animals [9]. The protocol was approved by the institutional Research Ethics Committee (ref no. 198-15). Drugs and chemicals were purchased from Sigma-Aldrich Corp. (St. Louis, MO, USA) unless mentioned otherwise. Female BALB/c mice (8 - 10 weeks old and about $30 \mathrm{~g}$ weight) were housed in cages at $24{ }^{\circ} \mathrm{C}$ in a $12 \mathrm{~h}$ light-dark cycle and were acclimatized for a week before experimentation. Animal feed and water were available ad libitum.

\section{Ovalbumin sensitization and challenge}

The mice were sensitized by intraperitoneal injection of $20 \mu \mathrm{g}$ of ovalbumin (OVA) in $0.1 \mathrm{~mL}$ of Alum (aluminium hydroxide powder) on days 0 and 14. The phosphate-buffered saline (PBS) was used as a vehicle for OVA. On days 27, 28,
47, 61, and 73 - 75, mice were subjected to intranasal OVA $(500 \mu \mathrm{g})$ or PBS in the control group [10,11].

\section{Treatment groups}

In addition to the normal control (NC) group (sensitized and challenged with PBS), the OVAsensitized and challenged mice were divided at random into seven groups $(n=8)$ : positive control (PC) group (saline-treated), vehicletreated group, and five drug-treated groups. Drugs were given by inhalation for $15 \mathrm{~min}$ once/day for seven doses with the last dose given 5 - $6 \mathrm{~h}$ before the final OVA challenge. The drugs given included roflumilast $(R, 500 \mu \mathrm{g} / \mathrm{kg})$ [12], formoterol (Fo, $50 \mu \mathrm{g} / \mathrm{kg}$ ) [10], fluticasone $(F, 1000 \mu \mathrm{g} / \mathrm{kg})[13,14]$, roflumilast + fluticasone $(\mathrm{R}+\mathrm{F}, 500+1000 \mu \mathrm{g} / \mathrm{kg})$ and formoterol + fluticasone (Fo + F, $50+1000 \mu \mathrm{g} / \mathrm{kg}$ ) [13, 15]. Dimethyl sulfoxide (DMSO) was used as a vehicle for the drugs.

\section{Transmission electron microscopy}

Mice were sacrificed by cervical dislocation. Immediately after animal dissection, lung specimens $\left(1-2 \mathrm{~mm}^{3}\right)$ were fixed in $2.5 \%$ cold glutaraldehyde. Specimens were washed in cacodylate buffer $(\mathrm{pH} 7.2)$ three times $(20 \mathrm{~min}$ each), post-fixed in $1 \%$ osmium tetraoxide for 2 $\mathrm{h}$, dehydrated in rising grades of ethanol, and embedded in Epon-araldite mixture. Semithin sections (1.0 $\mu \mathrm{m}$ thick) were cut from the embedded blocks, stained with toluidine blue, and then examined by light microscopy. The areas suitable for examination by electron microscopy were determined and ultrathin sections ( $50-70 \mathrm{~nm}$ thick) were obtained by the LKB ultramicrotome. The sections were stained with uranyl acetate and lead citrate. They were examined by transmission electron microscope (TEM) (100 CXII;JEOL, Ltd., Tokyo, Japan), and photomicrographed by a digital camera (XR - 41) [16].

\section{Statistical analysis}

Data are expressed as mean \pm SEM and were analysed with SPSS 18. Comparisons were made using Student's t-test for two groups and one-way analysis of variance (ANOVA) with Tukey's test for more than two groups. $P<0.05$ was considered statistically significant.

\section{RESULTS}

In the toluidine blue stained sections (Figure 1), TEM images of bronchioles and alveolar tissue 

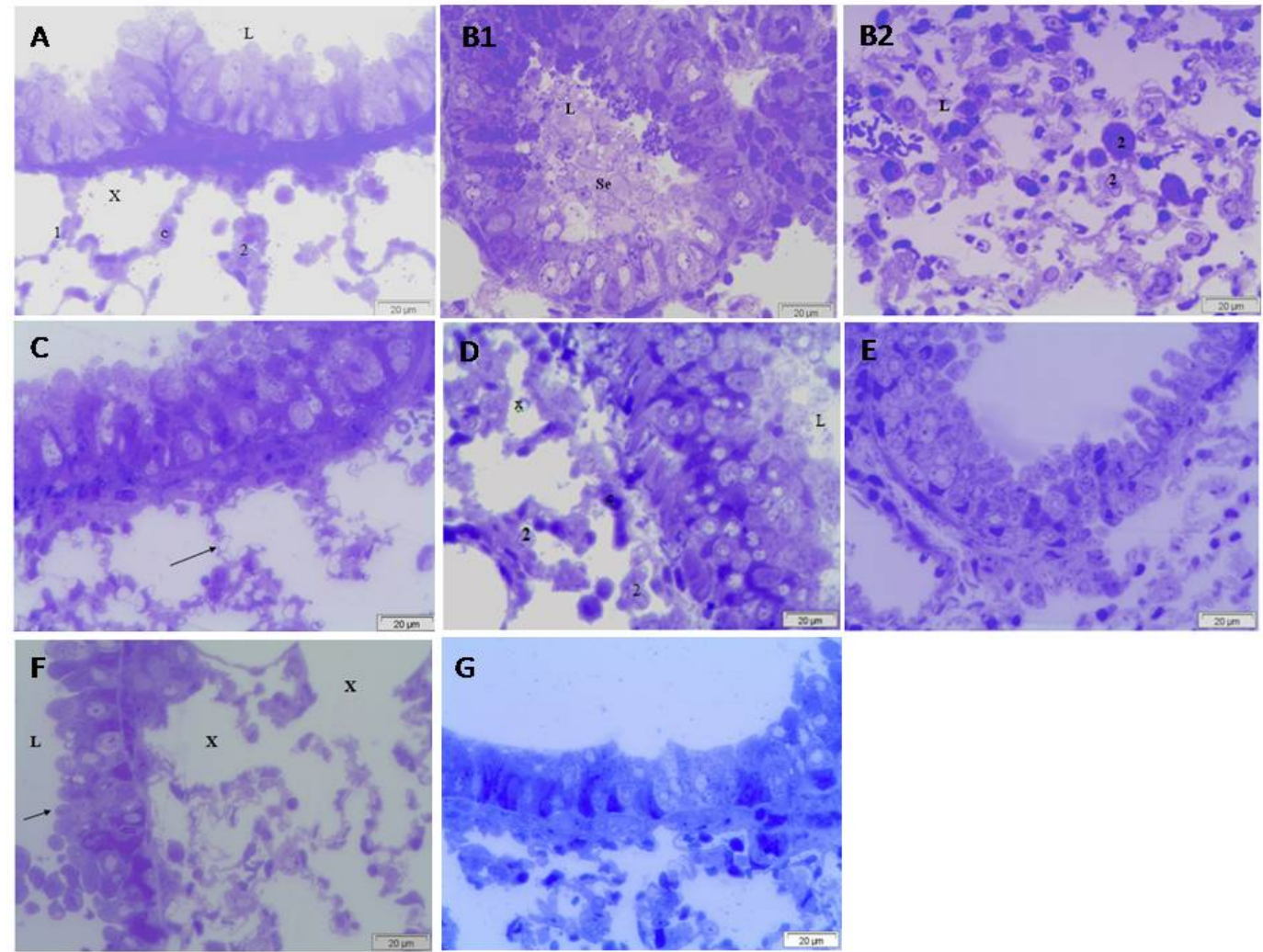

Figure 1: Micrographs of lung stained by toluidine blue $(x 200)$ in untreated and treated ovalbumin-asthmatic mice. (A) Normal control group showing that the bronchiolar wall formed by a thin fibrous layer and lined by Clara cells and few ciliated cells. The lumen (L) is free from secretions. The peribronchiolar alveoli show empty alveolar lumen $(\mathrm{x})$. The alveolar septa are thin and formed by flattened elongated cells (pneumocyte type I) (1), few large cells (pneumocyte type II) (2), and septal capillaries (c). (B) Positive control: (B1, B2) group: [B1] showing marked degenerative changes of the bronchiolar epithelium. The lumen $(L)$ contains abundant amounts of secretions (Se), [B2] showing that the alveolar septa are thickened and the population of pneumocyte type II (2) is increased with marked hypertrophy. The alveolar lumens (L) are mostly narrow. (C) Roflumilast group, (E) Fluticasone group, and (G) Formoterol + fluticasone group showing that the bronchioles have swollen Clara cells with deeply stained cytoplasmic granules. The ciliated cells are numerous and deeply stained. The bronchiolar wall is formed by a thin fibrous layer. The peribronchiolar alveoli show distention and their septal walls show a membranous structure (arrow), slight thickening, congestion of septal capillaries, and few pneumocytes (D) Formoterol group showing that the bronchiolar lining epithelium is formed from an increased population of Clara cells which appear faintly stained with deeply stained granules. The ciliated cells are compressed and embedded between Clara cells. The lumen $(L)$ contains secretory material. The peribronchiolar alveoli show thickened septal wall and congestion of septal capillaries. The alveolar lumen contains faintly stained material and cellular debris (x). (F) Roflumilast + fluticasone group showing that the bronchiolar wall is formed by a thin fibrous wall and is lined by Clara cells containing deeply stained granules. The ciliated cells appear deeply stained, and embedded between Clara cells. The lumen (L) is empty. The alveolar septa are thin

(Figure 2 and Figure 3), PC group showed marked ultrastructural changes as compared to NC group. These changes were markedlyreversed in the roflumilast + fluticasone group and moderately-reversed in the roflumilast, fluticasone, and formoterol + fluticasone groups while not-reversed in the formoterol group.

The increases in the airway basement membrane thickness and alveolar septal wall thickness were marked in the PC and formoterol groups, moderate in the roflumilast, fluticasone, and formoterol + fluticasone groups, and mild in the roflumilast + fluticasone group (Table 1).

\section{DISCUSSION}

In the current study, the asthmatic mice showed marked degenerative changes of bronchiolar epithelium cells. The alveolar septal walls were thickened with cellular changes and capillary congestion. The basement membranes showed marked thickening and the airway lumens contained abundant mucinous secretions. Previously, similar ultrastructural airway changes were detected in chronic OVA-asthmatic mice [17]. 

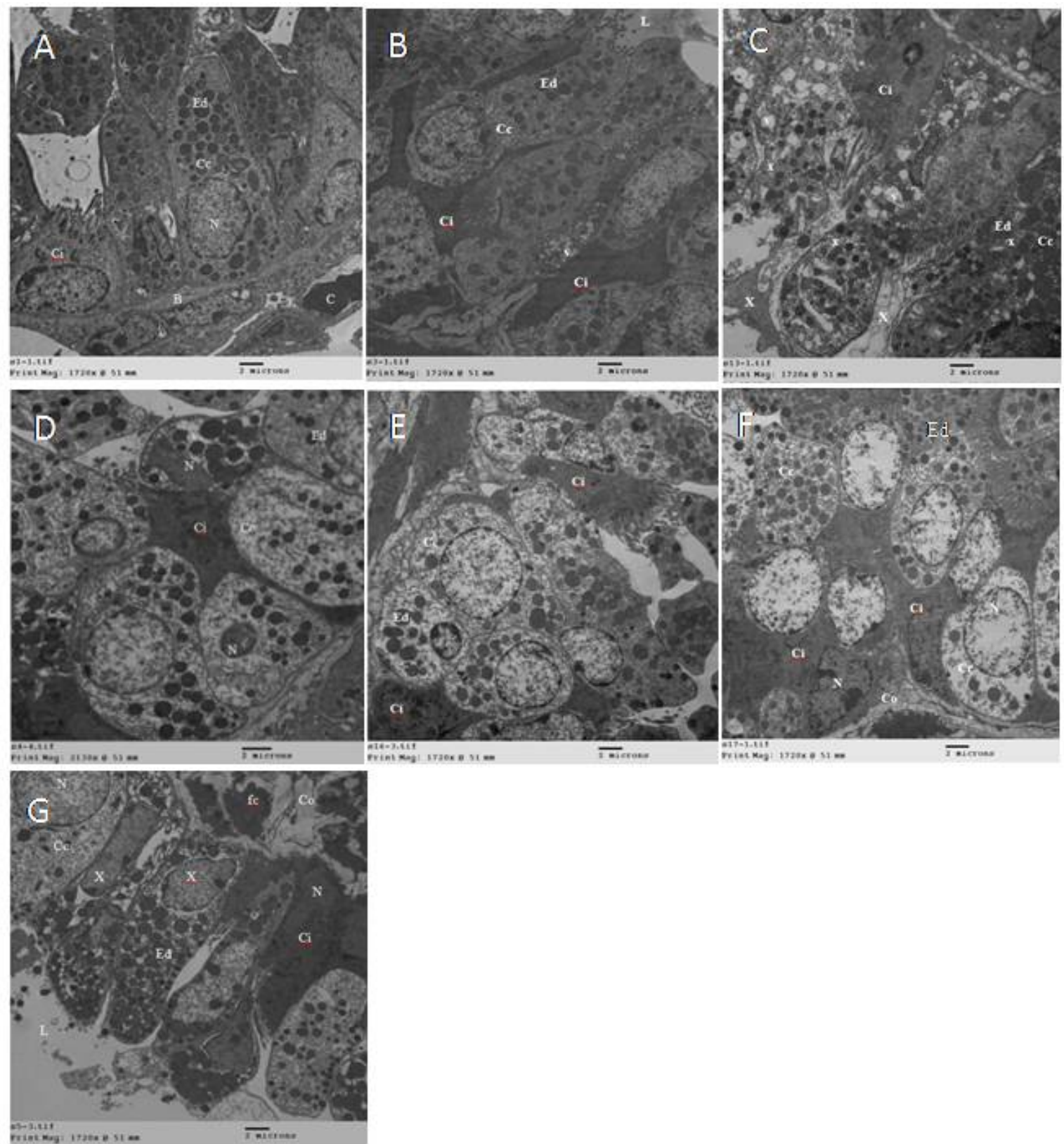

Figure 2: Transmission electron microscopy (TEM) micrographs of lung bronchioles stained by uranyl acetate and lead citrate (x2900) in untreated and treated ovalbumin-asthmatic mice. (A) Normal control group: showing that the epithelial lining of the bronchiole is formed from few ciliated cells (Ci) and numerous Clara cells (Cc) which have large vesicular nuclei $(\mathrm{N})$ and a large amount of cytoplasmic electron dense (Ed) secretory granules beside the cell organelles. Both types of cells are situated on the basement membrane (B). The bronchiolar wall is formed from a thin fibrous layer containing a capillary $(\mathrm{C})$. (B) Positive control group: showing swollen and sometimes ruptured Clara cells $(\mathrm{Cc})$ and the electron dense (Ed) secretory granules are markedly reduced. The ciliated epithelial cells $(\mathrm{Ci})$ appear compressed and more electron dense, and some of them contain numerous vacuoles (v). The lumen (L) contains light electron dense mucinous secretion. (C) Roflumilast group, (E) Fluticasone group, and (G) Formoterol + fluticasone group showing that Clara cells (Cc) contain moderate amount of electron dense (Ed) secretory granules, dilated rough endoplasmic reticulum (RER), and numerous large vacuoles $(\mathrm{v})$. The ciliated cells $(\mathrm{Ci})$ show numerous variable size electron dense (Ed) cytoplasmic bodies. The bronchiolar lumen contains a small amount of secretion (x). (D) Formoterol group showing swollen and vacuolated Clara cells (Cc) with marked reduction of the cytoplasmic electron dense (Ed) secretory granules and occasional pyknotic nuclei $(\mathrm{N})$. The ciliated cells $(\mathrm{Ci})$ are compressed with increased cytoplasmic electron density. (F) Roflumilast + fluticasone group showing that the bronchiolar epithelium is formed from both $\mathrm{Cc}$ and $\mathrm{Ci}$ cells situated on the basement membrane. The Clara cells $(\mathrm{Cc})$ contain large vesicular nuclei $(\mathrm{N})$ and a large amount of cytoplasmic electron dense (Ed) secretory granules. The ciliated cells $(\mathrm{Ci})$ are shorter with more electron dense cytoplasm and vesicular nuclei. The bronchiolar wall is formed from thin fibrous collagen layer (Co). Scale bar, $2 \mu \mathrm{m}$. 

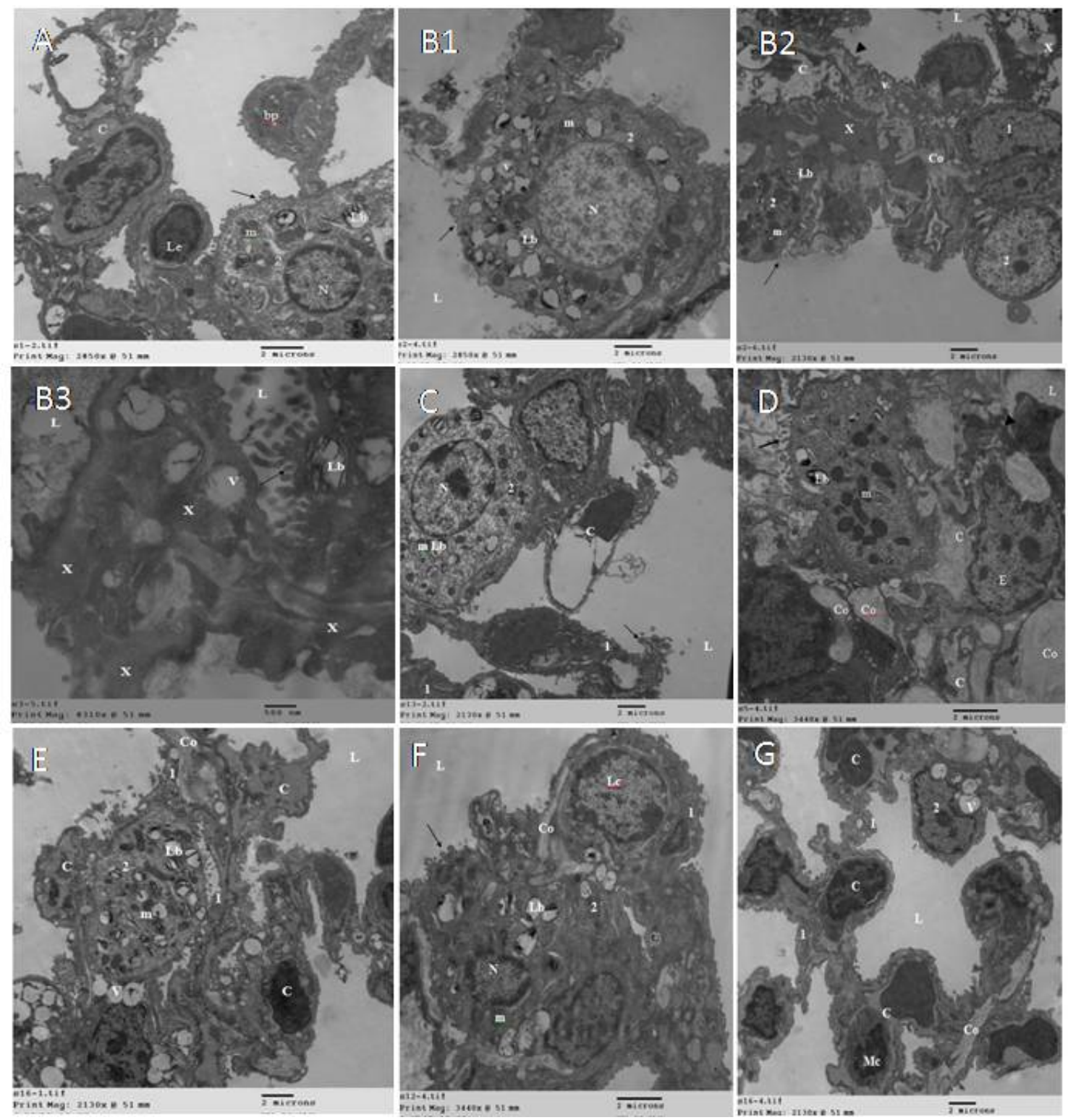

Figure 3: Transmission electron microscopy (TEM) micrographs of lung alveoli stained by uranyl acetate and lead citrate (x2900) in untreated and treated ovalbumin-asthmatic mice. (A) Normal control group: Alveolar cells include pneumocytes type I (1) and pneumocyte type II (2) which contains lamellar bodies (Lb), mitochondria $(\mathrm{m})$, and large vesicular nuclei $(\mathrm{N})$ with short luminal microvilli (arrow). Septalcapillary $(\mathrm{C})$ contains RBCs, blood platelets (bp) and leukocytes (Le). (B) Positive control (B1, B2, B3 groups): [B1] Hypertrophied pneumocytes type II (2) with large vesicular nuclei $(\mathrm{N})$, numerous mitochondria $(\mathrm{m})$, many lamellar bodies (Lb) and vacuoles (v), and few luminal microvilli (arrow), [B2] Markedly-thickened septal wall due to collagen (Co) and dilated septal capillary (c). Pneumocyte type I (1) contains numerous vacuoles (v). Alveolar lumen contains electron dense membranous structure (arrow), [B3] Markedly-thickened basement membrane (arrow). Pneumocyte type II (2) contains numerous lamellar bodies (Lb) or vacuoles (v). Alveolar lumen (L) contains cellular debris and secretions (x). (C) Roflumilast group, (E) Fluticasone group, and (G) Formoterol + fluticasone group: Alveolar septa contain capillaries (C), hypertrophied pneumocyte type II (2) containing large vesicular nuclei $(\mathrm{N})$, few lamellar bodies $(\mathrm{Lb})$, mitochondria $(\mathrm{m})$, and free ribosomes. Pneumocyte type I (1) appears elongated and covered with electron dense membranous material (arrow). Alveolar lumen (L) is empty. (D) Formoterol group: thickened alveolar septa with collagen (Co) and congested septal capillaries (C). Hypertrophied pneumocytes type II (2) containing numerous lamellar bodies (Lb), moderate amount of mitochondria $(\mathrm{m})$, and RER with surface microvilli (arrow). Pneumocyte type I (1) are flattened and covered with electron dense membranous threads (arrow). Alveolar lumen (L) contains small amount of light electron dense material. (F) Roflumilast + fluticasone group: Alveolar lumen $(\mathrm{L})$ is empty and septal wall contains pneumocyte type II (2) which has a vesicular nucleus $(\mathrm{N})$, mitochondria $(\mathrm{m})$, and lamellar bodies (Lb) with luminal microvilli (arrow). Pneumocyte type I (1) is elongated. Septal wall contains collagen fiber (Co) and lymphocyte (Lc) with dilated septal capillary. Scale bar, $2 \mu \mathrm{m}$. 
Table 1: Effects of treatments on the airway basement membrane thickness $(\mathrm{nm})$ and alveolar septal wall thickness $(\mu \mathrm{m})$ in ovalbumin-induced asthma in mice

\begin{tabular}{|c|c|c|c|c|c|c|c|}
\hline Group & NC & PC & $\mathbf{R}$ & Fo & $\mathbf{F}$ & $\mathbf{R + F}$ & Fo+F \\
\hline Airway basement & 265.75 & 517.38 & 399.50 & 506.63 & 405.88 & 303.63 & 394.50 \\
\hline $\begin{array}{l}\text { membrane thickness } \\
(\mathrm{nm})\end{array}$ & \pm 12.03 & $\stackrel{ \pm}{ \pm}$ & $24.01^{t+t+t \dagger}$ & $22.13^{t+\dagger}$ & $17.61^{\frac{ \pm}{\dagger, t+, t+\dagger}}$ & $13.90^{t, t+, t+\dagger}$ & $25.40^{ \pm t+t+t}$ \\
\hline Alveolar septal wall & 2.09 & 4.97 & 3.48 & 4.50 & 3.70 & 2.53 & 3.56 \\
\hline thickness $(\mu \mathrm{m})$ & \pm .13 & \pm .16 & $\pm 0.18^{* *}$ & $\pm 0.17^{\star \star \star}$ & $0.17^{ \pm, * * *}$ & $0.19^{ \pm}$ & \pm 0.20 \\
\hline
\end{tabular}

Treatments $(\mu \mathrm{g} / \mathrm{kg} /$ day by inhalation for $15 \mathrm{~min}$ for 7 days) included $\mathrm{R}$ (roflumilast, 500 ), Fo (formoterol, 50 ), $\mathrm{F}$ (fluticasone, 1000), R + F (roflumilast + fluticasone, 500+1000), and Fo + F (formoterol + fluticasone, $50+1000)$ $(\mathrm{n}=8)$. The image-pro plus software was used. Data are expressed as mean \pm SEM. Comparisons were made using ANOVA with Tukey's post-hoc test. ${ }^{\dagger} ; p<0.05: R+F$ vs. $R$ \& Fo $+F(p=0.017 \& 0.028$ respectively), $F$ vs. Fo $(p=0.010),{ }^{+t} ; p<0.01: R, F, \& F o+F$ vs. $P C(p=0.002,0.003, \& 0.001$ respectively $), R \& F o+F$ vs. Fo $\left(p=0.005 \& 0.003\right.$ respectively), $R+F$ vs. $F(p=0.009),{ }^{t+t} ; p<0.001$ : all treatments (except $\left.R+F\right) v s . N C, R+$ Fvs. PC \& Fo. ${ }^{*} ; p<0.05: F$ vs. Fo $(p=0.028),{ }^{* *} ; p<0.01: R$ vs. Fo $(p=0.002), R+F$ vs. $R \& F o+F(p=0.004$ \& 0.002 respectively), Fo $+F$ vs. Fo $(p=0.005),{ }^{* * *} ; p<0.001$ : all treatments (except $\left.R+F\right)$ vs. NC, all treatments (except Fo) vs. PC, R+F vs. Fo \& F.

The numbers of Clara cells and ciliated epithelial cells decreased while the numbers of goblet cells increased with numerous secretory granules containing mucus. The basement membrane was thickened due to deposition of collagen. The myofibroblast sheath was also thickened due to high content of collagen and myofibroblasts in addition to smooth muscle hypertrophy and hyperplasia. The bronchial epithelium was shrunken with pyknotic nuclei. Moreover, there were platelet activation and inflammatory cell infiltration in the perivascular and peribronchiolar areas. In the airway smooth muscle, the mitohcondria increased in number with ultrastructural changes. . In another study in OVA -sensitized and -challenged mice, changes of the epithelial phenotype were detected especially in the proximal airways. The toluidine blue-stained sections showed a significant increase in goblet cells which completely compensated the significant decrease in Clara cells and the non-significant decrease of ciliated cells. Consequently, the epithelial thickness significantly increased due to replacement of the smaller Clara cells by the larger mucous cells (mucous cell metaplasia). In the distal airways, there were no significant differences regarding the total number of epithelial cells per unit area of the basement membrane, the thickness of epithelium, and the different cell types [16]. In another study, the EM examination of biopsies obtained by fibreoptic endoscopy showed that airway myositis was characterized by a direct interaction between airway smooth muscle cells, mast cells, and lymphocytes. The smooth muscle remodeling was manifested by muscle cell hypertrophy and abnormal extracellular matrix deposition [18].

The current results showed that the ovalbumininduced ultrastructural airway changes were markedly-reversed in the roflumilast + fluticasone group, moderately-reversed in the roflumilast, fluticasone, and formoterol + fluticasone groups, while not-reversed in the formoterol group. Previously it was found that ICS have a little effect on airway remodeling in vivo as shown by failure to decrease collagen deposition in lungs of asthmatic patients which may be due to inability to inhibit TGF- $\beta 1$ expression [19]. Moreover, in OVA-sensitized rats, concomitant inhalation of fluticasone during OVA exposure partly inhibits airway remodeling and hyperresponsiveness while its inhalation after OVA exposure had no effect on remodeling [20]. Fortunately, roflumilast was found to decrease airway inflammation, deposition of subepithelial collagen, and epithelial thickening in a murine model of asthma [21]. In addition, oral roflumilast effectively reduced bleomycin-induced lung $\alpha$-I collagen transcripts and fibrosis in both preventive and therapeutic protocols in rodents while oral glucocorticoids were ineffective in the therapeutic protocol [22].

Failure of long acting $\beta 2$ agonists (formoterol) to improve remodeling in the current study agrees with a previous study which showed that in OVA -sensitized and -challenged BALB/c mice, LABA treatment (salmeterol) exaggerated airway inflammation, remodeling, and hyperresponsiveness due to mucus metaplasia, while fluticasone separately or combined with salmeterol reduced airway inflammation and remodeling [10].Moreover, aerosolized combined salmeterol and fluticasone in rats reversed goblet cell hyperplasia, but increased fibronectin and collagen in the airway wall [23]. In addition, in asthmatic patients adding salmeterol to ICS reduced airway muscular tone and improved expiratory flows, but exerted a little effect on remodeling shown by decreasing number of vessels in the airway lamina propria [24]. 


\section{CONCLUSION}

Co-inhalation of roflumilast and fluticasone significantly improved the ultrastructural airway changes than co-inhalation of formoterol and fluticasone in ovalbumin-asthmatic mice. This highlights the importance of adding roflumilast to fluticasone in asthma therapy due to its beneficial anti-inflammatory and antifibrotic effects. Due to species variations in the airway epithelium where most remodeling changes occur, the conclusions from this study cannot be readily extrapolated to human. Thus, clinical studies are recommended in this regard.

\section{DECLARATIONS}

\section{Acknowledgement}

This paper contains the results and findings of a research project that is funded by King Abdulaziz City for Science and Technology (KACST). Grant no. ARP-34-64.

\section{Conflict of Interest}

No conflict of interest associated with this work.

\section{Contribution of Authors}

The authors declare that this work was done by the authors named in this article and all liabilities pertaining to claims relating to the content of this article will be borne by them.

\section{Open Access}

This is an Open Access article that uses a funding model which does not charge readers or their institutions for access and distributed under the terms of the Creative Commons Attribution License (http://creativecommons.org/licenses/by/ 4.0) and the Budapest Open Access Initiative (http://www.budapestopenaccessinitiative.org/rea d), which permit unrestricted use, distribution, and reproduction in any medium, provided the original work is properly credited.

\section{REFERENCES}

1. Hamilton L, Davies D, Wilson S, Kimber I, Dearman R, Holgate $S$. The bronchial epithelium inasthma--much more than a passive barrier. Monaldi Arch Chest Dis 2001; 56: 48-54.

2. Bergeron C, Tulic MK, Hamid Q. Airway remodelling in asthma: from benchside to clinical practice. Can Respir J 2010; 17: e85-e93.
3. Bara I, Ozier A, De Lara JT, Marthan R, Berger P. Pathophysiology of bronchial smooth muscle remodelling in asthma. Eur Respir J 2010; 36: 11741184.

4. Payne DN, Rogers AV, Ädelroth E, Bandi V, Guntupalli $K K$, Bush A, Jeffery PK. Early thickening of the reticular basement membrane in children with difficult asthma. Am J Respir Crit Care Med 2003; 167: 78-82.

5. Rizzo MCV, Solé D. Inhaled corticosteroids in the treatment of respiratory allergy: safety vs. efficacy. $J$ Pediatr (Rio J) 2006; 82: S198-S205.

6. Montuschi P, Pagliari G, Fuso L. Pharmacotherapy of asthma: regular treatment or on demand? Ther Adv Respir Dis 2009; 3: 175-191.

7. Banner KH, Press NJ. Dual PDE3/4 inhibitors as therapeutic agents for chronic obstructive pulmonary disease. Br J Pharmacol 2009; 157: 892-906.

8. Murad HA, Habib HS, Rafeeq MM, Sulaiman MI, Abdulrahman AS, Khabaz MN. Co-inhalation of roflumilast, rather than formoterol, with fluticasone more effectively improves asthma in asthmatic mice. Exp Biol Med (Maywood) 2017; 242(5): 516-526.

9. Council NR. Guide for the care and use of laboratory animals: National Academies Press, 2010.

10. Riesenfeld EP, Sullivan MJ, Thompson-Figueroa JA, Haverkamp HC, Lundblad LK, Bates JH, Irvin CG. Inhaled salmeterol and/or fluticasone alters structure/function in a murine model of allergic airways disease. Respir Res 2010; 11-22.

11. Henderson Jr WR, Tang L-o, Chu S-j, Tsao S-m, Chiang GK, Jones $F$, Jonas M, Pae C, Wang H, Chi EY. A role for cysteinyl leukotrienes in airway remodeling in a mouse asthma model. Am J Respir Crit Care Med 2002; 165: 108-116.

12. Medvedova I, Prso M, Eichlerova A, Mokra D, Mikolka P, Mokry J. Influence of roflumilast on airway reactivity and apoptosis in ovalbumin-sensitized Guinea pigs. Adv Exp Med Biol 2014; 838: 11-18.

13. Mortaz E, Rad MV, Johnson M, Raats D, Nijkamp FP, Folkerts $G$. Salmeterol with fluticasone enhances the suppression of IL-8 release and increases the translocation of glucocorticoid receptor by human neutrophils stimulated with cigarette smoke. J Mol Med (Berl) 2008; 86: 1045-1056.

14. Vanacker N, Palmans E, Pauwels R, Kips J. Dose-related effect of inhaled fluticasone on allergen-induced airway changes in rats. Eur Respir J 2002; 20: 873-879.

15. Price D, Hillyer EV. Fluticasone propionate/formoterol fumarate in fixed-dose combination for the treatment of asthma. Expert Rev Respir Med 2014; 8: 275-291.

16. Reader JR, Tepper JS, Schelegle ES, Aldrich MC, Putney LF, Pfeiffer JW, Hyde DM. Pathogenesis of mucous cell metaplasia in a murine asthma model. Am J Pathol 2003; 162: 2069-2078.

17. Leishangthem GD, Mabalirajan U, Singh VP, Agrawal A, Ghosh B, Dinda AK. Ultrastructural changes of airway in murine models of allergy and diet-induced metabolic syndrome. ISRN allergy 2013: 261297: 1-13.

Trop J Pharm Res, November 2017; 16(11): 2643 
18. Begueret $H$, Berger $P$, Vernejoux J, Dubuisson $L$, Marthan R, Tunon-de-Lara J. Inflammation of bronchial smooth muscle in allergic asthma. Thorax 2007; 62: 815.

19. Chakir J, Shannon J, Molet S, Fukakusa M, Elias J, Laviolette M, Boulet L-P, Hamid Q. Airway remodelingassociated mediators in moderate to severe asthma: effect of steroids on TGF- $\beta, I L-11, I L-17$, and type I and type III collagen expression. J Allergy Clin Immunol 2003; 111: 1293-1298.

20. Vanacker NJ, Palmans E, Kips JC, Pauwels RA. Fluticasone inhibits but does not reverse allergeninduced structural airway changes. Am J Respir Crit Care Med 2001; 163: 674-679.

21. Kumar RK, Herbert C, Thomas PS, Wollin L, Beume R, Yang $M$, Webb DC, Foster PS. Inhibition of inflammation and remodeling by roflumilast and dexamethasone in murine chronic asthma. J Pharmacol Exp Ther 2003; 307: 349-355.

22. Cortijo J, Iranzo A, Milara X, Mata M, Cerdá-Nicolás $M$, Ruiz-Saurí $A$, Tenor $H$, Hatzelmann A, Morcillo $E$. Roflumilast, a phosphodiesterase 4 inhibitor, alleviates bleomycin-induced lung injury. Br J Pharmacol 2009; 156: 534-544.

23. Vanacker NJ, Palmans E, Pauwels RA, Kips JC. Effect of combining salmeterol and fluticasone on the progression of airway remodeling. Am J Respir Crit Care Med 2002; 166: 1128-1134.

24. Orsida BE, Ward C, Li X, Bish R, Wilson JW, Thien F, Walters $E H$. Effect of a long-acting $\beta 2$-agonist over three months on airway wall vascular remodeling in asthma. Am J Respir Crit Care Med 2001; 164: 117-121. 